\title{
IJOURNAL.RU
}

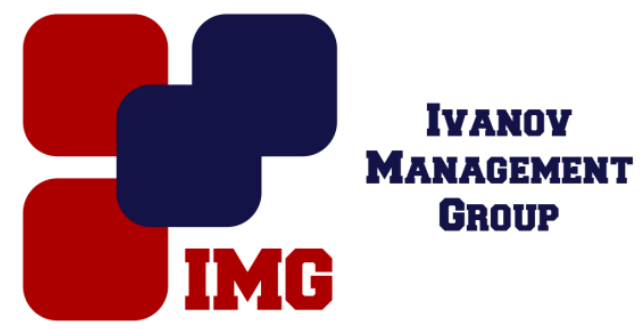

Агаркова O.A.

Оренбургский государственный университет Оренбург, Россия

doi: $10.18411 / 1 \mathrm{j}-31-07-2017-12$

idsp 000001:1j-31-07-2017-12

\section{Приветствие в национальных языках жителей Оренбуржья}

\section{Аннотация}

В настоящей статье рассматривается национально-культурная специфика речевого поведения жителей Оренбургской области. Автор исследует формулы приветствия в национальных языках наиболее многочисленных представителей области.

Ключевые слова: Оренбургская область, речевой этикет, речевое поведение, приветствие, национальный язык, национальная культура.

\section{Abstract}

National and cultural specific of habitants' speech behavior in the Orenburg region is examined in the present article. The author probes the greeting formulas of representatives of the most numerous nationalities in the region.

Keywords: Orenburg region, speech etiquette, speech behavior, greeting, national language, national culture.

Оренбургская область исторически формировалась как многонациональный регион, который граничит с тремя областями Республики Казахстан, Татарстаном и Башкортостаном. Традиции межкультурного взаимодействия сформировали у жителей открытость к новым коммуникациям, готовность к этнокультурному диалогу. В. В. Амелин отмечает, что «проблема изучения совместимости культур народов, проживающих в Оренбургском крае, 
актуальна и является важнейшим индикатором стабильности их совместного проживания» [1].

По данным Портала Оренбургской области, среди представителей 126 национальностей, русские, татары, казахи, украинцы, башкиры, мордва, чуваши, немцы, армяне имеют численность более десяти тысяч человек [6].

Многовековое совместное проживание славянских, тюркских, финноугорских и других народов способствует развитию межнациональной коммуникабельности, частью которой является речевой этикет (система правил речевого поведения), определяемый культурными традициями общества.

Приветствие - один из самых важных знаков речевого этикета. С его помощью устанавливается контакт общающихся, определяются отношения между людьми. Любой разговор, как правило, начинается с приветствия, оно может быть вербальным и невербальным. У многих народов выбор приветствия зависит не только от возраста, пола и степени близости общающихся, но также от времени суток, рода занятий и т.д. Этикет каждого народа имеет свои особенности, которые мы рассмотрим на формулах приветствия наиболее многочисленных представителей Оренбургской области.

Устойчивее других в современной русской речи оказались приветствия утренние, дневные, вечерние: «Доброе утро!», «Добрый день!», «Добрый вечер!», которые широко используются наряду с «Здравствуйте!», «Здравствуй!».

В татарском языке установление контакта при общении начинается с приветствия «Ассяламягаляйкем!». Наиболее употребительными считаются «Исянмесез!» (Здравствуйте!), «Хяерлеиртя!»(Доброе утро!),«Хяерле кон!»(Добрый день!),«Хяерлекич!» (Добрый вечер!). Несколько просторечными и фамильярными являются приветствия «Нихял?»(Как дела?), «Саумы?» (букв. Здоров ли?), «Саумысез!» (букв. Здоровы ли вы), «Сялам!» (Привет!)[9].

Инициальные формулы казахского языка идентичны рассмотренным выше: «Qaiyrlytang!» (Доброе утро!), «Qaiyrlyku’n!» (Добрый день!), «Qaiyrlykesh!» (Добрый вечер!), «Sa'lem» (Привет!), «Sa'lemetsizbe!» (Здравствуйте!), «Sizdiko’rgenimequanyshtymyn!» (Рад(а) Вас видеть!), «Zhagdaiyngyzqalai?» (Как Ваши дела?), «Qandaizhangalyqtarbar?» (Какие новости?) [3].

Для украинского языка характерны приветствия: «Здрастуйте!» (Здравствуйте!), «Привіт!» (Привет!), «Яку вас справи?» (Как у вас дела?), «Доброго ранку!» (Доброе утро!), «Доброго дня!» (Добрый день), 
«Доброговечора!» (Добрый вечер), «Добраніч!» (Доброй ночи), «Всімпривіт!» (Всем привет!)[7].Согласно украинским обычаям, хозяин приветствует гостя традиционными фразами: «Доброго дня!»,«Доброго здоров'я [здоров’ячка]!»,«Вітаємо, вітаємо!»,«Гості до нас!»,«Загостіть, коли ласка ваша!», которые предназначены для каждодневного использования.Средипросторечных высказываний распространенным является: «Здоровенькібули!»и приветствия религиозного содержания: «Дай, Боже, щасливу годину!»,«Дай, Боже [день добрий, щастя, здоров’я] !»,«Помагай, Боже!» и др.

А. Ю. Сынбулатова отмечает, что «в башкирской коммуникативной культуре приветствие является важным элементом общения«һаумы(һығыз)!», Исәнме (-һегез)!»(наиболее распространенные выражения). Формулы «Хәйерлекөн!»(Добрый день!), «Хәйерлеиртә!»(Доброе утро!), «Хәйерле кис!»(Добрый вечер!)представляются кальками с русских формул. Среди молодежи распространены следующие приветствия:«һаумы!»,«Шәпме!»,«Сәләм!». Общемусульманскоеприветствие «әссәләмәғәләйкүм -вәғләәйкүмэссәләм» (Мир Вам!)употребляется в речистаршего поколения. Существуют также приветствия для людей, занятых работой,приветствия-осведомления, приветствия при неожиданной встрече и т.д.» $[8$, с. $17-18]$.

По мнению исследователя речевого этикета Волго-Уралья В. Кузнецова, «приветственные слова и выражения в речи современных мокшан так же многообразны как и у рассмотренных выше народов:«Парарьсема!» (Привет!), «Шумбрат!» (Здравствуй!,Доброе утро!,Добрый день!,Добрый вечер!,Здорово!), «Шумбратада!» (С добрым утром!, Добрый день!, Добрый вечер!), «Кода тиньэрятада?» (Как вы поживаете?)[5, с.206; 310-311].

Наиболее часто приветственные формулы употребляются при входе в чьелибо жилище и при встрече на улице:«Андямо паро-чи: ков молят?» (Добрый человек: куда идешь?), «Бог помочь!» (Бог помочь!), «Кода эрят-аштят?» (Как поживаешь?), «Кодаттевтне?»(Как дела?), «Лембесюк пря!» (Горячий привет!), «Мезтьтейнят?»(Что поделываешь?), «Пароарсемат!»/«Паромельсэсовакшнодо!»(Добро пожаловать!), «Сюкпря!» (Привет!), «Уледешумбрат!»/«Шумбратадо!» (Здравствуйте!), «Шумбрачи!»(Доброе утро!,Добрый день!,Добрый вечер!), «Шумбрат!»(Здравствуй!, Здорово!)[5, с.214; 312]. 
У А. В. Кузнецова находим, «что традиционное приветствие в чувашском языке носит форму диалога (вопроса-ответа)?Говоря друг другу «Салам!»(Привет!), «Салам алейкӗм!»(Мир вам!, Здравствуйте!), «Салам алейкум!»/«Салам аликке̌м!»/«Саламалик!» (Мир вам!), «... сенченхӗрўллӗ салам!» (От ... горячий привет!), «Сывӑ-и?»(Здоров(ы) ли?), «Сывлӑхӑрмӗнле?» (Как ваше здоровье?), «Ырӑирпултӑр!»(Доброе утро (пусть будет)!), «Ырӑкас (пултӑр)!»(Добрый вечер (пусть будет)!), «Ырӑ кун (пултӑр)!»(Добрый день (пусть будет)!), «Ырӑ кун сунатӑп!»(Доброго дня желаю!)представители общества выражают доброжелательное отношение к окружающим: показывают желание вступить в контакт: продлить знакомство. [5, с.62-63; 284-285].

Р. А. Газизов отмечает, что «универсальная формула «GutenTag!», употребляемая в официальной и нейтральной обстановке общения в немецком языке, имеет следующие разговорные варианты: «Tag!», «'n Tag!». Большое многообразие разговорных вариантов имеет также приветствие «Hallo!»(Привет!): «Hallochen!»/«Hallöchen!»(Приветик!), «Ні!»(Салют!), «Неу!»(Салютик!)[4].

Армяне приветствуют друг друга выражениями: «Барев!» (Здравствуй!), «Баревдзез!» (Здравствуйте!), «Бари луйс!» (Доброе утро!), «Бари ор!» (Добрый день!), «Бари ереко!» (Добрый вечер!), «Вохчуйн!» (Привет!), «Бари галуст!» (Добро пожаловать!)[2].

Итак, нами были рассмотрены формулы приветствия (универсальные и специфические) в национальных языках жителей Оренбуржья, которые связывают людей друг с другом, укрепляют контакты, способствуют бесконфликтному общению. Приветствие не имеет информативного значения, но обладает особой значимостью в человеческом общении. Исследуемая коммуникативно-речевая система национально-специфического поведения направлена на желание вступить в контакт,построение доброжелательных отношений и гармоничное общение представителей разных лингвокультур. 
1. Амелин В. В.Межкультурные взаимодействия в условиях полиэтнической области (пример русских и татар в Оренбуржье). URL:http://www.tatarhistory.narod.ru/orenburg.htm (дата обращения: 25.07.2017).

2. Армянский язык, Армения, Ереван, самоучитель.URL: http://www.hayeren.do.am>index/0-11(дата обращения: 25.07.2017).

3. Асанов Ж. К., Рогалев В. П. 100 слов и выражений на казахском языке. URL:http://www.parlam.kz/3/blogs/AsanovJ/Details/11/3253(дата обращения: 25.07.2017).

4. ГазизовР.А. Коммуникативное поведение немцев и русскихв этикетных ситуациях общения //Русское и немецкое коммуникативное поведение. -Воронеж,2002. Выпуск 1. - С. 7-22.

5. Кузнецов А. В. Речевой этикет народов Волго-Уралья: Монография. - М.: Федеральное агентство по культуре и кинематографии Российской Федерации; Чебоксары: Чувашский государственный институт гуманитарных наук, 2008. - 320 с.

6. Портал Правительства Оренбургской области: Оренбуржье многонациональное. URL: http://www.orenburg-gov.ru/Info/OrbRegion/Population/Nations/ (дата обращения: 25.07.2017).

7. Русско-украинский

URL:https://www.tourister.ru/world/europe/ukraine/publications/498(дата

разговорник. 20.07.2017).

8. Сынбулатова А. Ю. Башкирский речевой этикет: семантика и средства выражения: автореф. дисс. ... к. филол. н. -Уфа, 2011. - 26 с.

9. Татарский речевой этикет. URL:http://nazaccent.ru/content/6769-tatarskij-rechevojetiket.html (дата обращения: 25.07.2017). 